\title{
Nilai Pendidikan Karakter terhadap Rasulullah dalam Karya Raja Ali Haji
}

\author{
Abdul Malik*, Isnaini Leo Shanty \\ Prodi Pendidikan Bahasa dan Sastra Indonesia, Universitas Maritim Raja Ali Haji, \\ Tanjungpinang, Indonesia
}

Pengiriman: 15/10/2020; Diterima: 28/05/2021; Publikasi: 29/06/2021

DOI: 10.31629/kiprah.v9i1.2647

\begin{abstract}
Abstrak
Tulisan ini merupakan hasil penelitian tentang nilai pendidikan karakter terhadap Rasulullah dalam karya Raja Ali Haji. Lima karya dianlisis dalam penelitian ini, yakni Syair Abdul Muluk, Gurindam Dua Belas, Tsamarat al-Muhimmah, Tuhfat al-Nafis, dan Syair Sinar Gemala Mestika Alam, menggunakan teori semiotika Pierce. Berhubung dengan itu, digunakan metode deskriptif-kualitatif dan teknik analisis isi. Temuan penelitian ini terdapat tiga belas nilai pendidikan karakter terhadap Rasulullah dalam karya Raja Ali Haji. Jadi, nilai-nilai itu dapat digunakan sebagai materi pembelajaran pendidikan karakter, baik dalam pendidikan informal, formal, maupun nonformal.
\end{abstract}

Kata kunci: karya Raja Ali Haji; nilai; pendidikan karakter; Rasulullah

\begin{abstract}
Absract
This paper is the result of research on the value of character education to the Prophet Muhammad in the Raja Ali Haji's works. Five works were analyzed in this study, namely Syair Abdul Muluk, Gurindam Dua Belas, Thamarat al-Muhimmah, Tuhfat al-Nafis, and Syair Sinar Gemala Mestika Alam, using Pierce's semiotic theory. In this connection, descriptive-qualitative methods and content-relational analysis techniques were used. The findings of this study are that there are thirteen values of character education for the Prophet Muhammad in the Raja Ali Haji's works. Thus, these values can be used as learning material for character education, both in informal, formal and non-formal education.
\end{abstract}

Keywords: character education; Prophet Muhammad; Raja Ali Haji’s work; value

\section{PENDAHULUAN}

Sesuai dengan visi pendidikan nasional, sejak 2010 telah disiapkan delapan program kerja. Salah satu programnya adalah penyiapan bahan pengembangan pendidikan budaya dan karakter bangsa. Menurut Pusat Kurikulum (2010), nilai-nilai yang dikembangkan dalam pendidikan karakter bersumber dari agama, Pancasila, dan budaya (Malik, Dahnuss, \& Shanty, 2019).

Dalam budaya Melayu Kepulauan Riau, nilai-nilai karakter itu terdapat di dalam berbagai karya sastra, budaya, dan kearifan lokal yang menjadi bagian dari budaya Melayu. Oleh karena itu, karya-karya Raja Ali Haji (1809-1873) umumnya mengandungi nilai-nilai budaya Melayu yang bersumber dari ajaran agama Islam (Malik \& Shanty, 2019; Malik \& Shanty, 2017; Malik, 2015; Bachmid, 2005). Pasalnya, Raja Ali Haji hidup di lingkungan masyarakat dan budaya yang menjunjung tinggi nilai-nilai karakter sebagai pedoman hidup (Nor \& Dahlan, 2018; Lapsley, 2016; Malik, 2008).

Di dalam karya beliau Gurindam Dua Belas, pada Pasal Kelima, bait 1, Raja Ali Haji 
(Haji, 1847) mengatakan, "Jika hendak mengenal orang berbangsa, lihatlah kepada budi dan bahasa." Kenyataan itu menunjukkan bahwa beliau memandang keberadaan karakter atau budi pekerti sangat mustahak bagi manusia. Dengan demikian, karakter merupakan bagian penting dari jati diri suatu bangsa. Karena kehalusan atau ketinggian budi pekertilah, seseorang dan atau suatu bangsa menjadi mulia dan terhormat (Malik, 2012: 559-560).

Istilah karakter sama dengan budi pekerti dalam budaya Melayu dan budaya Indonesia umumnya. Budi pekerti terbentuk dari budi yang merupakan maujud abstrak (Malik, 2015; Malik \& Shanty, 2019). Wujud budi tak terlihat karena berada dalam pikiran dan perasaan. Ia diketahui setelah menyatu dengan sifat, sikap, perkataan, watak, dan perilaku.

Dalam budaya Melayu konsep budi dan budi pekerti atau karakter berhubung dengan nilai-nilai Islam. Hal itu karena budaya Melayu berbaur dengan nilai-nilai Islam (Malik, 2015; Malik \& Shanty, 2017). Sebagai contoh, di dalam budaya Melayu anak-anak wajib menghormati orang tuanya. Jika ketentuan itu dilanggar, anak disebut durhaka, tak berbudi pekerti, dan atau berkarakter buruk. Kenyataan itu sejalan dengan ajaran Islam yang mewajibkan umatnya memuliakan orang tua.

Menurut Bukhari al-Jauhari dalam karyanya Taj al-Salatin (Braginsky, 1994), budi terdiri atas 14 ciri, antara lain, merupakan entitas terdekat dengan Allah, yang menyebabkan manusia dapat membedakan antara kebaikan dan keburukan. Haji (1987; Yunus (Ed.), 1987) mengemukakan bahwa budi memuliakan manusia, mencegah manusia berbuat salah, memungkinkan manusia mendapatkan pengetahuan yang sulit-sulit. Cahaya budi memancar naik ke dan mengendalikan otak (pikiran) sehingga seseorang dapat membedakan kebenaran dengan kesalahan dan kebaikan dengan keburukan.

Fungsi hati, sebagai tempat asal budi, menjadi jelas dengan merujuk konsep bahasa Arab. Rahman, et al., (2010), mengemukakan bahwa dalam bahasa Arab terdapat beberapa kata yang merujuk kepada 'hati' dalam bahasa Indonesia, tetapi memiliki kedalaman makna yang berlapis-lapis. Lapisan itu meliputi qalb yaitu dimensi hati terluar, ke dalam lagi ada fuâd yaitu dimensi hati yang merujuk kepada akal yang berupa potensi kecerdasan intelektual, lebih ke dalam ada pula tsaqâfah yaitu dimensi hati yang mengandungi kecerdasan rohani, seterusnya ada $l u b b$ yang mengandungi semua kecerdasan intelektual dan kecerdasan rohani. Dimensi hati yang terdalam adalah sirr, yakni rahasia kerohanian yang terdalam.

Budi bersumber dari sirr di lapisan hati yang paling dalam. Ia merupakan rahasia kerohanian paling dalam, paling suci, paling sakral, dan paling dekat dengan Allah. Lapisan kerohanian terdalam dari hati itulah yang menerima petunjuk langsung dari Allah tentang kebenaran dan kesalahan serta kebaikan dan keburukan. Sirr membentuk kehalusan dan atau ketinggian budi karena ia bukan dimensi fisis, melainkan metafisis (Malik \& Shanty, 2017).

Syaidina Ali menyampaikan wasiat putranya agar mengingat Allah untuk mendapatkan ketenangan hati. Hati memiliki kehidupan (dengan dzikrullah) dan kematian, ia juga harus tenteram dan tenang ketika menerima beberapa kesulitan. Hati pun mampu meyakini hakikat dan kebenaran. Hati mempunyai dua sisi: yang bersifat Ilahiyah, mengarah kepada kebaikan dan yang bersifat hewani dan syaitaniah, mengarah kepada kejahatan. Kenyataan itu memengaruhi keinginan manusia (Yazdi, 2012).

Hubungan hati dengan lapisan-lapisannya yang melahirkan budi digambarkan dalam Gambar 1 


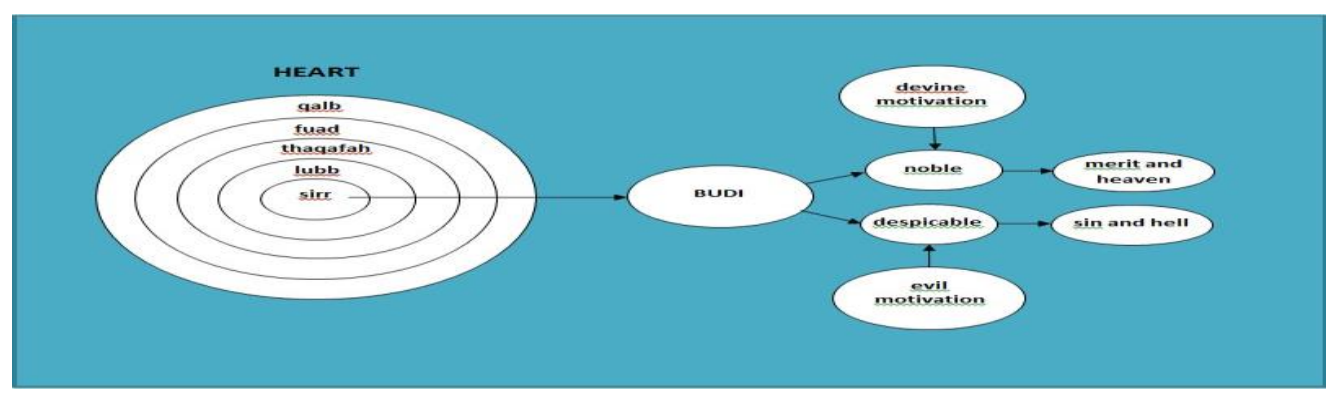

Gambar 1 Hubungan antara Hati dan Budi (Malik \& Shanty, 2019)

Gambar 1 menggambarkan budi yang baik mewujudkan kemuliaan. Ia berasal dari keinginan yang bermotivasi Ilahiyah. Sebaliknya, budi yang buruk menyebabkan kehinaan. Itu bersumber dari dorongan syaitaniyah.

Kata pekerti berarti 'penampilan, pelaksanaan, aktualisasi, tabiat, dan atau perilaku'. Berhubung dengan itu, secara etimologis, budi pekerti yang semakna dengan karakter berarti 'perilaku atau penampilan diri yang berbudi' (Malik, 2012).

Dalam pendekatan etika, budi pekerti atau karakter adalah watak atau tabiat khusus seseorang untuk berbuat sopan dan menghargai pihak lain yang tercermin dalam perilaku dan kehidupannya. Watak itu merupakan semua dorongan, sikap, keputusan, kebiasaan, dan nilai baik dalam diri seseorang, yang terhimpun dalam istilah kebajikan (Zuriah, 2008; Malik, Subroto, Shanty, \& Agust, 2020).

Dalam perspektif psikologi, karakter atau budi pekerti mengandungi watak moral yang baku dan melibatkan keputusan berdasarkan nilai-nilai hidup. Menurut Hurlock (dalam (Malik \& Shanty, 2019), watak manusia dapat dilihat pada perilakunya yang diatur oleh usaha dan kehendak berdasarkan hati nurani, yang menjadi pengendali penyesuaian diri dalam kehidupan bermasyarakat.

Karakter berkaitan dengan akhlak dalam Islam. Kata akhlak merupakan bentuk jamak yang berasal dari bahasa Arab, khuluq. Artinya 'adat kebiasaan, perangai, tabiat, watak, adab, agama, sifat asal, marwah, gambaran batin, dan atau budi pekerti' (Alfan, 2011; Gazalba, 1981). Konsep akhlak meliputi sajiyyah 'perangai', mur'uah 'budi', thab'in 'tabiat', dan $a d a b$ 'sopan santun' (Alfan, 2011).

Konsep akhlak berdasarkan ajaran Islam, yang dibentuk oleh rukun iman dan rukun Islam melalui proses ihsan, ikhlas, dan takwa (Gazalba, 1981). Budi pekerti semakna dengan akhlak. Budi yang baik akan melahirkan budi pekerti atau akhlak yang mulia. Budi pekerti atau akhlak itulah yang membentuk karakter manusia.

Masalah penelitian ini adalah "Apa sajakah nilai pendidikan karakter terhadap Rasulullah yang terdapat di dalam karya Raja Ali Haji?" Sesuai dengan masalah itu, penelitian ini bertujuan untuk menganalisis nilai pendidikan karakter terhadap Rasulullah dalam karya Raja Ali Haji. Pada gilirannya, diharapkan nilainilai luhur hasil penelitian ini mampu menjadi penangkal penetrasi budaya asing yang negatif dan tidak sesuai dengan karakter bangsa Indonesia (Malik, 2014).

\section{METODE PENELITIAN}

Berdasarkan sifat datanya, penelitian ini tergolong penelitian deskriptif-kualitatif. Kajian deskriptif-kualitatif merupakan penelitian yang menggunakan data kualitatif, yang berhubung dengan semua informasi yang dijumpai dan tak berbentuk numerik. Penelitian jenis ini termasuk metodologi yang kompleks dan cakupannya sangat luas, yang dapat meliputi beberapa jilid buku (Trochim, 2000). 
Nilai pendidikan karakter dikaji dalam penelitian ini dengan pendekatan semiotika karena objeknya sistem tanda (sign). Semiotika berkaitan dengan tanda yang dikomunikasikan (Bakar, 2006). Peirce menganggap bahwa manusia berpikir dalam tanda (sign). Tanda merupakan unsur penting dalam komunikasi agar komunikasi berlangsung efisien (Malik \& Shanty, 2017).

Zoest (1993) mengemukakan bahwa setiap sesuatu dapat dianggap sebagai tanda. Syaratnya sesuatu itu membuat hubungan segitiga dengan ground, denotatum, dan interpretant. Menurut Peirce (Pateda, 2001; Sobur, 2006), tanda "is something wich stands to somebody for something in some respect or capacity." Sesuatu yang digunakan agar tanda berfungsi disebut ground. Konsekuensinya, tanda (sign atau representamen) selalu terdapat dalam hubungan triadik: ground, object, dan interpretant (Peirce, 1982; Innis, 1982).

Tanda berhubung pula dengan denotatum atau objek. Zoest (1993) menjelaskan denotatum adalah kenyataan yang ditunjuk oleh sesuatu tanda. Peirce membagi tiga jenis tanda berdasarkan sifat hubungan antara tanda dan denotatum-nya. Ketiga tanda tersebut adalah icon (ikon), index (indeks), dan symbol (simbol). Di dalam pendekatan semiotika, tanda, objek, dan makna membentuk hubungan segitiga. Penanda mewakili objek yang menjadi petanda (Eco, 1976; Littlejohn, 1996). Penerima menghubungkan tanda dengan objek dan makna. Dari hubungan itu diperoleh interpretant, yang berfungsi sebagai perantara antara penanda dan petanda. Makna tanda berada di dalam pikiran penerima setelah dia menghubungkan tanda dengan objek (Cobley \& Jansz, 1999).

Karya sastra dengan keutuhannya, berdasarkan semiotika, merupakan tanda. Sebagai suatu bentuk, karya sastra secara tertulis mempunyai sifat keruangan (Santosa,
1993). Dimensi ruang dan waktu di dalam cerita rekaan mengandungi perilaku tandamenanda yang menyiratkan makna semiotis.

Dalam literary semiotics karya sastra harus disikapi dengan literary discourse. Dalam hal ini, sasaran kajian ilmiah sastra bukan pada maujud konkret wacananya, melainkan metadiscourse atau bentuk dan ciri-ciri kewacanaan yang tak dapat diamati secara konkret (Aminuddin, 1997). Dalam penelitian sastra dengan pendekatan semiotika, indeks yang paling banyak dicari yaitu tanda yang menunjukkan hubungan sebab-akibat (Preminger, 1974).

Lima karya Raja Ali Haji yang menjadi objek kajian ini: (1) Syair Abdul Muluk, SAM (Haji dalam Syamsiar, S. (Ed.), 1989; Syamsiar, (Ed.), 1989), (2) Gurindam Dua Belas, GDB (Haji, 1847), (3) Tsamarat alMuhimmah, TAM (Haji dalam Malik (Ed.), 2013; Malik, 2013; Mahdini, 1999),

Tuhfat al-Nafis, TAN (Ahmad \& Haji, 1982; Matheson, 1982), dan (5) Syair Sinar Gemala Mustika Alam, SGMA (Haji dalam Malik \& Junus, 2000).

Data penelitian ini dianalisis dengan menggunakan teknik analisis isi. Dalam hal ini, yang dikaji adalah isi karya Raja Ali Haji terpilih. Konsep yang diteliti berupa nilai-nilai karakter, hanya dapat ditemukan setelah dianalisis isi karya-karya tersebut. Analisis isi tergolong penelitian deskriptif (Ary, Jacobs, \& Razavieh, 1982). Kajian ini termasuk analisis isi-relasional karena meneliti hubungan antara konsep-konsep pendidikan karakter di dalam kalimat dan paragraf (prosa) juga baris dan bait (puisi). Bahkan, juga dikaji wacana secara menyeluruh (Stephenson, 2000).

\section{HASIL DAN PEMBAHASAN}

Berdasarkan hasil analisis data, ditemukan tiga belas nilai pendidikan karakter terhadap Rasulullah dalam karya Raja Ali Haji. Nilainilai tersebut terdapat pada Tabel 1 berikut ini. 
A. Malik, I. L. Shanty/ Jurnal Kiprah 9 (1) (2021) 8-22

Tabel 1 Nilai Pendidikan Karakter terhadap Rasulullah dalam Karya Raja Ali Haji

\begin{tabular}{|c|c|c|c|c|c|c|}
\hline \multirow[b]{2}{*}{ No. } & \multirow[b]{2}{*}{ Indeks } & \multicolumn{5}{|c|}{ Karya Raja Ali Haji } \\
\hline & & SAM & GDB & TAN & TAM & SGMA \\
\hline 1 & 2 & 3 & 4 & 5 & 6 & 7 \\
\hline 1. & $\begin{array}{l}\text { Mengimani } \\
\text { Rasulullah }\end{array}$ & - & - & Hlm. 24 & - & Bait 3-19 \\
\hline 2. & $\begin{array}{l}\text { Meyakini berkah } \\
\text { dari Rasulullah }\end{array}$ & Bait 916 & - & - & - & - \\
\hline 3. & $\begin{array}{l}\text { Bersalawat kepada } \\
\text { Rasulullah }\end{array}$ & - & Hlm. 1 & - & Hlm. 21 & Bait 1 \\
\hline 4. & $\begin{array}{l}\text { Memuliakan } \\
\text { Rasulullah }\end{array}$ & Bait 618 & - & - & $\begin{array}{l}\text { Hlm. 23, } \\
\text { Bait } 3\end{array}$ & - \\
\hline 5. & $\begin{array}{l}\text { Mengikuti ajaran } \\
\text { Rasulullah }\end{array}$ & - & - & - & Hlm. 22 & - \\
\hline 6. & $\begin{array}{l}\text { Meyakini } \\
\text { kelebihan } \\
\text { Rasulullah }\end{array}$ & - & - & - & - & Bait 14-16 \\
\hline 7. & $\begin{array}{l}\text { Meyakini } \\
\text { Rasulullah Nabi } \\
\text { yang terakhir }\end{array}$ & - & - & - & - & Bait 17 \\
\hline 8. & $\begin{array}{l}\text { Meyakini mukjizat } \\
\text { Rasulullah }\end{array}$ & - & - & - & - & Bait 20 \\
\hline 9. & $\begin{array}{l}\text { Meyakini } \\
\text { kesempurnaan } \\
\text { Rasulullah }\end{array}$ & - & - & - & - & Bait 26 \\
\hline 10. & $\begin{array}{l}\text { Memperjuangkan } \\
\text { agama Rasulullah }\end{array}$ & - & - & - & - & Bait 69-73 \\
\hline 11. & $\begin{array}{l}\text { Mencintai } \\
\text { Rasulullah }\end{array}$ & - & - & - & - & Bait 91 \\
\hline 12. & $\begin{array}{l}\text { Mengharapkan } \\
\text { syafaat dari } \\
\text { Rasulullah }\end{array}$ & - & - & - & - & Bait 95 \\
\hline 13. & $\begin{array}{l}\text { Berdoa melalui } \\
\text { Rasulullah }\end{array}$ & - & - & - & - & Bait 96 \\
\hline
\end{tabular}

Tabel 1 di atas memuat 13 nilai pendidikan karakter terhadap Rasulullah dalam karya Raja Ali Haji. Ketiga belas nilai itu adalah (1) mengimani Rasulullah, (2) meyakini berkah dari Rasulullah, (3) berselawat kepada Rasulullah, (4) memuliakan Rasulullah, (5) mengikuti ajaran Rasulullah, (6) meyakini kelebihan Rasulullah, (7) meyakini Rasulullah nabi yang terakhir, (8) meyakini mukjizat Rasululah, (9) meyakini kesempurnaan Rasulullah, (10) memperjuangkan agama Rasululllah, (11) mencintai Rasulullah, (12) mengharapkan syafaat dari Rasulullah, dan (13) berdoa melalui Rasulullah (tawasul).

Sesuai dengan teori semiotik yang digunakan dalam penelitian ini (Zoest, 1993; Malik \& Shanty, 2019), ketiga belas nilai itu diperikan Haji dengan menggunakan indeks, yaitu tanda yang menunjukkan hubungan sebab-akibat. Dalam hal ini, Haji mengemukakan nilai-nilai pendidikan karakter terhadap Rasulullah dengan menggunakan empat kategori tanda (indeks).

Pertama, qualisign ikonik rhematik, yakni dengan memerikan sifat dan sikap yang sedia ada atau memang melekat dalam diri manusia. Contohnya, Raja Opu La Maddusilat merupakan Raja Bugis pertama masuk agama Islam karena beriman kepada Rasulullah.

Kedua, sinsign indeksikal rhematik, yakni dengan mengemukakan kualitas karakter yang dimiliki manusia yang dapat dilihat, diamati, dan didengar perkataan maupun perbuatan mereka. Sebagai contoh, Nabi Daud berkisah kepada Ibunda Rasulullah, dalam mimpi 
beliau, akan kelebihan anak (Muhammad) yang dikandung perempuan mulia itu.

Ketiga, legisign indeksikal dicent, berupa kualitas berdasarkan norma atau peraturan diyakini oleh Haji, yakni ajaran agama Islam. Contohnya, ketiga belas nilai karakter tersebut merupakan ajaran Islam sesuai dengan pedoman Alquran dan hadis. Umat Islam meyakininya berasarkan ajaran agamanya yang terdapat di dalam Alquran dan atau hadis.

Keempat, argument, yakni pernyataan langsung Haji sebagai penulis tentang nilai karakter yang dimaksud. Misalnya, penulis mengharapkan syafaat dari Rasulullah dalam SGMA, bait 95, yang dituturkan langsung oleh Haji berdasarkan keyakinannya.

Dengan menggunakan keempat kategori tanda itulah, diperikan nilai pendidikan karakter terhadap Rasulullah. Berdasarkan keempat kategori tanda itu, ditemukan tiga belas nilai pendidikan karakter terhadap Rasulullah seperti yang tercantum pada Tabel 1 di atas. Berikut ini pembahasan ketiga belas nilai tersebut.

\section{Mengimani Rasulullah}

Karakter manusia yang berhubung dengan Rasulullah ditandai oleh adanya keimanan kepada Baginda. Amanat itu terkandung di dalam karya Raja Ali Haji, antara lain, dalam TAN berikut ini.

“... Syahadan adalah Raja Opu La Maddusilat inilah awal Raja Bugis yang mulamula masuk agama Islam yang berimankan Nabi kita Muhammad salla Allahu alaihi wasallam," (Ahmad \& Haji, 1982: 24).

Kutipan di atas menjelaskan keturunan Raja-Raja Bugis yang pertama memeluk agama Islam. Keislaman Raja Opu La Maddusilat ditandai dengan berimannya beliau kepada Rasulullah, yang berhubung dengan keberimanan kepada Allah. Secara tersirat, Haji menitipkan pesan bahwa hubungan manusia dengan Rasulullah itu sangat penting dan hal itu terjadi jika manusia mampu mengimani Rasulullah.

Lebih lanjut, karakter beriman kepada Rasulullah juga terkandung dalam SGMA
(Malik \& Junus, 2000). Hal itu terdapat pada syair bait 3-19. Berikut ini kutipan bait 7 syair tersebut.

Bulan kedelapan Nabi Sulaiman

Datang dengan kesukaan iman

Memberi khabar yang keterangan

Buntingkan Nabi akhirul zaman

Bait syair di atas merupakan bagian dari kisah yang menceritakan peristiwa ketika Rasulullah masih di dalam kandungan ibunda Baginda. Dalam bulan-bulan kehamilan Baginda itu Ibunda Rasulullah terus didatangi arwah para nabi terdahulu. Bait syair di atas bercerita tentang kedatangan Nabi Sulaiman. Nabi Sulaiman menyampaikan bahwa beliau pun beriman kepada Rasulullah sebagai bukti kebenaran yang kelak akan dibawa oleh Rasulullah untuk menjadi berkah bagi alam semesta. Nabi Sulaiman memastikan bahwa tak ada nabi lagi setelah Rasulullah (Nabi akhirul zaman).

Kisah dalam bait syair di atas menyiratkan amanat agar manusia beriman kepada Rasulullah. Dengan demikian, beriman kepada Rasulullah tergolong karakter mulia.

Nilai karakter yang dikemukakan di atas sesuai dengan petunjuk Allah. "Orang-orang kafir dari ahli kitab dan orang-orang musyrik tiada menginginkan diturunkannya suatu kebaikan kepadamu dari Tuhanmu dan Allah menentukan siapa yang dikehendaki-Nya (untuk diberi) rahmat-Nya (kenabian); dan Allah mempunyai karunia yang besar," (Q.S. Al-Baqarah, 105).

Allah menegaskan, melalui firman-Nya di atas, bahwa Rasulullah memang dianugerahiNya rahmat kenabian. Oleh sebab itu, beriman kepada Rasulullah adalah wajib hukumnya bagi umat Islam. Dengan demikian, amanat karya-karya Raja Ali Haji di atas sejalan dengan pedoman Ilahi.

\section{Meyakini Berkah dari Rasulullah}

Sejalan dengan karakter beriman, karya Raja Ali Haji juga mengandung amanat agar manusia meyakini berkah dari Rasulullah. Amanat itu terdapat dalam SAM (Haji, 1989), bait 916 , berikut ini kutipannya. 
Tuan Syekh ketawa lakunya lillah

Serta berkata Insya Allah

\section{Berkat Nabi Muhammad Rasulullah}

\section{Hajatmu itu nescaya sampailah}

Bait syairnya di atas hendak meyakinkan pembacanya agar meyakini berkah dari Rasulullah. Berkah itu akan memungkinkan setiap hajat, harapan, dan tujuan baik yang hendak dicapai oleh orang-orang yang meyakininya akan dikabulkan Allah. Jadi, meyakini berkah dari Rasulullah merupakan karakter yang mulia dan terpuji.

Sebuah hadis menyatakan, "Sesungguhnya Nabi Muhammad Saw. biasa memberi makan unta, menyapu rumah, menambal sandal, menjahit pakaian, memerah susu kambing, makan bersama pelayan, dan menumbuk tepung jika pelayan berasa penat. Baginda tak malu membawa barang-barang dari pasar ke rumah keluarga Baginda, mengajak bersalaman dengan orang kaya dan miskin, memulai mengucapkan salam dan tak pernah meremehkan undangan sekalipun dalam acara makan kurma yang buruk. Baginda cepat kaki dan tangan, ramah, mulia, baik dalam bergaul, riang, banyak senyum tanpa ketawa, sedih tanpa bermasam muka, tawaduk tanpa merendahkan diri, dermawan tanpa berlebih-lebihan, halus perasaan, belas kasihan kepada semua orang Islam, tak pernah mengulurkan tangan kepada sesuatu yang diinginkan. Mudah-mudahan, rahmat Allah tetap dianugerahkan kepada Baginda, keluarga, dan sahabat-sahabat Baginda. Dan, mudah-mudahan Allah memberkahi, memuliakan, dan menghormati mereka," (H.R. Tirmidzi).

Hadis di atas menjamin bahwa orang-orang yang mencintai Rasulullah akan memperoleh berkah. Hal itu dimungkinkan karena Rasulullah memang menjadi sosok pribadi yang memperoleh rahmat dari Allah.

\section{Bersalawat kepada Rasulullah}

Karakter lain yang diperlukan manusia dalam perhubungannya dengan Rasulullah adalah bersalawat kepadanya, keluarganya, dan para sahabatnya. Haji mencontohkannya dengan memulai setiap karyanya dengan bersalawat kepada Rasulullah. Hal itu berarti seyogianya setiap manusia memulai pertuturan resmi dengan menggandengkan pernyataan pujian terhadap kebesaran Allah dan bersalawat kepada Rasulullah. Salawat berikut ini terdapat dalam TAM.

"Washalallahu 'ala Sayyidina Muhammadin wa Maulana Muhammadin nabiyil mub'utsu fi akhiri al-zamani wa 'ala alihi wa ashhabihi wa khulafa'ihi min ahli as-sidqi wal-iman," (Haji, 2013).

Petikan di atas merupakan kebiasaan yang dilakukan oleh Haji setiap memulai tulisan dalam karya beliau. Kutipan dari TAM membuktikan konsistensi sikap dan perilaku Haji dalam menerapkan keyakinannya dalam berkarya.

Haji juga memulai pendahuluan GDB dengan bersalawat kepada Rasulullah. Salawat dalam karya itu menggunakan bahasa Melayu, yang di dalamnya terdapat kata serapan dari bahasa Arab.

“... Salawatkan Nabi yang Akhir al-Zaman serta keluarganya dan sahabatnya sekalian adanya," (Haji, 1847: 1).

Dengan memberikan contoh bersalawat kepada Rasulullah setiap memulai tulisannya, Haji menyampaikan amanat secara tersirat bahwa kebiasaan itu tergolong perbuatan yang mulia dan terpuji. Dengan demikian, bersalawat kepada Rasulullah merupakan karakter yang diperlukan dalam perhubungan manusia dengan Rasulullah.

Nilai karakter di atas sesuai dengan firman Allah.

"Sesungguhnya, Allah dan malaikatmalaikat-Nya bersalawat untuk Nabi. Hai, orang-orang yang beriman! Bershalawatlah kamu untuk Nabi dan ucapkanlah salam penghormatan kepadanya," (Q.S. Al-Ahzab, 56).

Ajaran tentang bersalawat kepada Rasulullah memang diperintahkan oleh Allah kepada orang-orang yang beriman. Bahkan, Allah dan para malaikat pun, sesuai dengan firman-Nya, bersalawat kepada Rasulullah.

\section{Memuliakan Rasulullah}

Karakter yang berhubung dengan Rasulullah juga ditandai oleh ketulusan 
manusia, memuliakan Baginda. Hal itu dinyatakan oleh Haji dalam SAM (Haji dalam Syamsiar, S. (Ed.), 1989) pada bait 618.

\section{Suka ketawa berkata ia}

Berkat Nabi saidul anbiya

Serta berkat duli yang mulia

Luput daripada segala bahaya

Bait syair di atas berkisah tentang kebahagiaan dan kegembiraan yang dialami Wazir (Menteri) Suka. Menurutnya, kebahagiaan yang dirasakannya karena luput dari bahaya berkat Rasulullah dan Sultan Abdul Muluk, Raja Negeri Barbari. Hal itu berarti amanat yang tersirat pada bait syair itu adalah manusia harus memuliakan Rasulullah. Wazir Suka meyakini bahwa kebahagiaannya merupakan berkat dari Rasulullah karena dia memuliakan Baginda. Jadi, bait syair itu menegaskan amanat bahwa memuliakan Rasulullah tergolong karakter yang mulia.

Anjuran memuliakan Rasulullah juga dijumpai dalam TAM. Berikut ini petikannya.

“... Maka di dalam hal itu, di dalam dunia ini, berlebih-lebihan setengah atas setengah seperti anbia', aulia', dan ulama'. Maka yaitu lebih daripada segala orang yang 'am, yaitu tiada sebab lain, melainkan sebab ilmu yang dikaruniakan Allah Ta'ala kepadanya," (Haji, 2013: 23).

Kutipan di atas juga mengandung amanat keutamaan memuliakan Rasulullah. Dalam hal ini, kemuliaan yang menyertai Rasulullah dan para nabi yang lain (anbia') berkat ilmu yang dianugerahkan oleh Allah kepada Baginda. Oleh sebab itu, ketauladanan dari Rasulullahmengutamakan dan menghargai ilmu-harus diikuti oleh umatnya. Jelaslah amanatnya bahwa setiap manusia seyogianya memuliakan Rasulullah sebagai karakter mulia dalam perhubungan dengan Baginda.

Karya TAM juga memuat anjuran supaya manusia memuliakan Rasulullah yang dikemas dalam bentuk syair. Berikut ini nukilan bait 3 syair tersebut (Mahdini, 1999).

Nabi Muhammad rasul yang mulia

Ialah penghulu segala dunia

Barang siapa berimankan dia

\section{Dunia akhirat mendapat bahagia}

Melalui syairnya di atas, Haji meyakinkan pembacanya yang memuliakan Rasulullah akan mendapat kebahagiaan di dunia dan di akhirat. Hal itu berarti memuliakan Rasulullah tergolong karakter terpuji dalam perhubungan manusia dengan Rasulullah.

Nilai karakter yang diperikan di atas sejalan dengan firman Allah berikut ini.

"Dan, sesungguhnya kamu benar-benar berakhlak yang agung," (Q.S. Al-Qalam, 4).

Dengan firman-Nya di atas, Allah memuji Nabi Muhammad Saw. sebagai manusia yang berakhlak atau berbudi pekerti yang agung. Itulah jaminan Allah bahwa Baginda Rasulullah memang seseorang yang memiliki karakter yang mulia sehingga wajib dimuliakan oleh semua umatnya. Kenyataan itu sejalan dengan amanat dalam karya Raja Ali Haji.

\section{Mengikuti Ajaran Rasulullah}

Haji dalam TAM juga beramanat agar manusia mengikuti ajaran Rasulullah. Perkara itu dihubungkan dengan unsur yang paling utama dalam kehidupan manusia, yakni agama dan ilmu pengetahuan.

"Bermula adapun ilmu itu yaitu sabit kepada naqal dan akal. ... Adapun sabda Nabi shallahu 'alaihi wasallam, yakni 'Barang siapa dikehendaki Allah Ta'ala dengan kebajikan, diberi faham ia pada agama dan diberi ilmu ia dengan cerdik.'

Adapun kelebihan ilmu kepada akal, maka yaitu amat nyata dengan dalil yang mudah dan dengan pendapatan akal yang singkat pun boleh sampai...." (Haji, 2013: 22).

Nukilan di atas merupakan paparan tentang pentingnya pedoman agama dan kelebihan ilmu pengetahuan. Penuturan itu bersumberkan ajaran Rasulullah (lihat hadis yang dikutip oleh Haji dalam kutipan di atas). Secara tersirat, amanatnya adalah setiap manusia hendaklah mengikuti ajaran Rasulullah, termasuk memahami dan menghayati pentingnya agama dan ilmu bagi sesiapa pun yang hendak mengambil bekal di 
dunia untuk dibawa ke akhirat yang abadi. Ilmu itu haruslah benar menurut ajaran agama Islam.

Argumentasi yang dikemukakan Haji berdasarkan rujukan yang diyakininya benar. Jadi, mengikuti ajaran Rasulullah merupakan penanda karakter mulia dalam hubungan manusia dengan Rasulullah, yang sesuai dengan hadis berikut ini.

"Sesungguhnya, barang siapa yang hidup di antara kalian (panjang umurnya), maka dia akan mendapatkan perbedaan yang sangat banyak. Maka, hendaklah kalian berpegang teguh dengan Sunnahku dan sunnah para khulafaur rasyidin yang mendapat petunjuk. Gigitlah (peganglah) sunnah tersebut dengan gerahammu," (H.R. Abu Daud).

Dalam hadis di atas, Rasulullah menegaskan bahwa umat Islam wajib mengikuti ajaran Baginda. Dengan demikian, nilai karakter mulia mengaikuti ajaran Rasulullah yang dikemukakan oleh Raja Ali Haji memang bersumber dari ajaran Islam.

\section{Meyakini Kelebihan Rasulullah}

Keistimewaan lain Rasulullah adalah Baginda memiliki kelebihan dari semua nabi yang lain. Kenyataan itu mendapat perhatian Haji dan diungkapkan dalam SGMA (Malik \& Junus, 2000). Bait 14-16 karya tersebut mengisahkan kelebihan Rasulullah disampaikan secara berturut oleh Nabi Ismail, Nabi Musa, dan Nabi Daud. Berikut ini nukilan bait 16 .

\section{Bulan ketujuh juga dikata}

Nabi Allah Daud datanglah serta

\section{Kepada Aminah memberi warta}

\section{Kelebihan Nabi alam semesta}

Bait-bait syair di atas mengisahkan kedatangan para Nabi Allah menyampaikan kelebihan Rasulullah kepada Ibunda Baginda yang sedang mengandungkan Baginda. Pengakuan para Nabi Allah terdahulu itu menjadi bukti bahwa Rasulullah memang lebih istimewa daripada para nabi yang lain.

Kelebihan Rasulullah adalah Baginda diutus untuk menjadi rasul bagi seluruh umat manusia. Sebaliknya, para nabi sebelum Baginda hanya diutus terbatas untuk kaumnya masing-masing. Itulah salah satu rahmat kelebihan yang dianugerahkan oleh Allah kepada Rasulullah. Dengan demikian, meyakini kelebihan Rasulullah dibandingkan dengan para nabi sebelum Baginda merupakan karakter yang wajib dimiliki manusia, khasnya umat Islam, seperti yang terdapat dalam firman Allah berikut ini.

"Apa saja nikmat yang kamu peroleh adalah dari Allah dan apa saja bencana yang menimpamu, maka dari (kesalahan) dirimu sendiri. Kami mengutusmu menjadi Rasul kepada segenap manusia dan cukuplah Allah menjadi saksi," (Q.S. An-Nisaa', 79).

Firman Allah di atas menjelaskan bahwa Rasulullah diutus untuk menjadi rasul bagi seluruh umat manusia. Sebaliknya, para nabi sebelum Baginda hanya diutus untuk kaumnya saja. Itulah salah satu rahmat kelebihan yang dianugerahkan oleh Allah kepada Nabi Muhammad Saw. Dengan demikian, amanat Raja Ali Haji di atas sejalan dengan petunjuk Allah atau ajaran agama Islam. Dalam hal ini, argumen yang beliau kemukakan berdasarkan kebenaran yang bersumber dari Yang Mahabenar.

\section{Meyakini Rasulullah Nabi yang Terakhir}

Karya SGMA mengisahkan pula bahwa Rasulullah adalah nabi yang terakhir, tiada nabi lagi setelah Baginda. Amanat itu terekam pada bait 17 syair naratif tersebut (Malik \& Junus, 2000).

\section{Bulan kedelapan Nabi Sulaiman}

\section{Datang dengan kesukaan iman}

Memberi khabar yang keterangan

Buntingkan nabi akhirul zaman

Berita yang dibawa oleh Nabi Sulaiman dalam bait syair di atas berisi amanat bahwa Rasulullah adalah nabi yang penghabisan, tiada nabi lagi setelah Baginda (Buntingkan nabi akhirul zaman). Kenyataan itu mestilah dipercayai oleh orang-orang yang beriman. Oleh sebab itu, meyakini bahwa Rasulullah 
adalah penutup para nabi merupakan sifat, sikap, dan amalan yang mulia. Jadi, manusia yang meyakini tergolong memiliki karakter yang terpuji, yang memang terdapat di dalam hadis Rasulullah.

Rasulullah Saw. bersabda, "Adalah Bani Israel diperintah oleh nabi-nabi, setiap wafat seorang nabi, lalu diganti dengan nabi yang lain, tetapi sesudah aku tak ada lagi nabi (yang lain)," (H.R. Bukhari).

Hadis di atas membenarkan amanat yang terdapat di dalam karya Raja Ali Haji bahwa Nabi Muhammad Saw. adalah nabi yang terakhir. Dengan demikian, amanat karya itu menggunakan sumber ajaran agama Islam sehingga tak diragukan kebenaran dan kemuliaannya. Jadi, meyakini Rasulullah adalah nabi yang terakhir tergolong karakter baik yang wajib diterapkan oleh umat Islam terhadap Rasulullah.

\section{Meyakini Mukjizat Rasulullah}

Dalam SGMA (Malik \& Junus, 2000), terdapat amanat agar manusia memercayai bahwa Rasulullah memiliki mukjizat yang luar biasa. Amanat tersebut terdapat pada bait 20 .

Malam Isnin dua belas harinya

Dahulu sedikit daripada fajarnya

Masa diperanakkan oleh bundanya

Beberapa mukjizat zahir padanya

Syair di atas meyakinkan pembacanya bahwa Rasulullah sejak lahir ke dunia telah dikaruniai mukjizat oleh Allah. Oleh sebab itu, setiap manusia wajib meyakini kelebihan Baginda. Sesiapa pun yang meyakini mukjizat Rasulullah itu tergolong manusia yang berkarakter mulia.

"Dialah yang mengutus kepada kaum yang buta huruf seorang rasul di antara mereka, yang membacakan ayat-ayat-Nya kepada mereka, men-suci-kan mereka, dan mengajarkan mereka kitab dan Hikmah (AlSunnah). Dan, sesungguhnya mereka sebelumnya benar-benar dalam kesesatan yang nyata," (Q.S. Al-Jumu'ah, 2).

Di dalam firman-Nya di atas Allah menjelaskan bahwa Rasulullah mulanya buta aksara. Akan tetapi, dengan mukjizat yang dilimpahkan Allah kepada nabi-Nya itu, Rasulullah mampu membaca dan mengajarkan umatnya tentang sunahnya. Itulah antara lain mukjizat yang dimiliki oleh Rasulullah, dari buta aksara, lalu dengan rahmat Allah secara serta-merta, berubah menjadi fasih membaca sehingga Baginda dapat menyampaikan ayatayat Allah kepada umatnya untuk memperbaiki kehidupan mereka. Dengan demikian, nilai karakter yang dikemukakan oleh Haji sesuai dengan pedoman Allah.

\section{Meyakini Kesempurnaan Rasulullah}

Karya SGMA (Malik \& Junus, 2000) masih mengisahkan keistimewaan Rasulullah. Kali ini kesempurnaannya, di antaranya adalah ketika dilahirkan, Rasulullah telah sempurna, zahir-batin, tak seperti bayi-bayi yang baru lahir umumnya. Bait 26 syair itu bercerita tentang keistimewaan Rasulullah ketika dilahirkan.

Sifat diperanakkan Nabi kita

Terkerat pusat bercelak mata

Berkhatan memang khabar yang nyata

Dengan kodrat Tuhan semesta

Itulah di antara kesempurnaan Rasulullah ketika dilahirkan menurut Haji dalam Syair Sinar Gemala Mestika Alam. Begitu dilahirkan, pusat (pusar) Rasulullah sudah terkerat (terpotong) sehingga tak perlu dipotong oleh bidan yang membantu kelahiran Baginda. Selain itu, matanya sudah bercelak. Keistimewaan lainnya adalah Baginda lahir sudah dalam keadaan berkhatan. Keistimewaan itu tak dimiliki oleh manusia biasa. Kesemuanya itu bagian dari tanda-tanda kenabian dan kerasulan Baginda yang telah ditunjukkan oleh Allah sejak Rasulullah dilahirkan, bahkan sejak Baginda dalam kandungan ibundanya.

Dengan syair itu, Haji menyampaikan amanat bahwa setiap manusia, terutama orang beriman, harus yakin bahwa Rasulullah adalah manusia yang sangat sempurna, yang telah kelihatan sejak Baginda lahir. Jadi, meyakini kesempurnaan Rasulullah merupakan penanda 
karakter terpuji manusia, yang sesuai dengan hadits berikut.

Anas r.a. berkata, "Rasulullah adalah orang yang paling dermawan, paling tampan, dan paling pemberani," (H.R. Bukhâri dan Muslim).

Hadits di atas menjelaskan bahwa Allah mengaruniai Baginda Rasulullah dengan kesempurnaan jasmaniah dan rohaniah, yang tak dimiliki oleh manusia lain. Baginda Rasulullah yang terbaik dan teristimewa tampilan fisiknya dan paling sempurna karakternya. Jadi, umat Islam seyogianya meyakini kelebihan Rasulullah itu.

\section{Memperjuangkan Agama yang Dibawa Rasulullah}

Penanda nilai karakter yang terkandung di dalam karya Raja Ali Haji juga meliputi amanat untuk memperjuangkan agama Islam yang dibawa oleh Rasulullah. Amanat tersebut tersurat pada bait 69-73 SGMA (Malik \& Junus, 2000). Berikut ini disajikan nukilan bait 69.

\section{Nabi pun berhadap kepada kaumnya \\ Membawa firman amar nahinya \\ Kebanyakan Quraisy mendustakannya \\ Melainkan Abu Bakar membenarkannya}

Bait-bait syair di atas berkisah tentang perjuangan Rasulullah menyebarkan ajaran agama Islam. Beratnya perjuangan Baginda alami demi menjalankan perintah Allah. Secara tersirat, bait syair di atas mengajak umat Islam untuk terus berjuang, melanjutkan perjuangan Rasulullah, demi menyampaikan kebenaran yang diwahyukan oleh Allah untuk keselamatan manusia. Jadi, memperjuangkan agama Islam yang dibawa oleh Rasulullah merupakan wujud dari karakter terpuji manusia.

Kualitas karakter mulia memperjuangkan agama yang dibawa oleh Rasulullah dalam bait syair yang dikutip di atas, dimiliki oleh Abu Bakar Ash-Shiddiq dan sebagian bangsa Quraisy. Keyakinan itu memang sedia ada di dalam diri mereka. Karakter itu terbukti dari perjuangan mereka bersama Rasulullah.
Karakter tersebut sesuai dengan pedoman Allah berikut ini.

"Katakanlah, 'Inilah jalan (agama)-ku, aku dan orang-orang yang mengikutiku mengajak (kamu) kepada Allah dengan hujah yang nyata, Mahasuci Allah dan aku tiada termasuk orang-orang yang musyrik," (Q.S. Yusuf, 108).

Melalui firman-Nya di atas, Allah menganjurkan Nabi Muhammad Saw. untuk mengajak umat manusia mengikuti agamaNya. Itu adalah amanah Allah kepada Rasulullah dan semua umat Islam. Dengan demikian, sesiapa pun yang memperjuangkan agama Rasulullah membuktikan dirinya sebagai manusia yang memiliki karakter mulia.

\section{Mencintai Rasulullah}

Karya SGMA (Malik \& Junus, 2000) juga menyiratkan amanat agar umat Islam mencintai Rasulullah. Amanat itu, antara lain, terdapat pada bait 91 syair tersebut.

Serta kasih akan dianya

Sukakan olehmu mendengar kisahnya

Apa lagi bulan mauludnya

Harus dibesarkan itu waktunya

Jelaslah amanat syair di atas. Haji mengajak manusia mencintai Rasulullah dengan cara, antara lain, suka mendengarkan kisah Baginda dan membesarkan hari lahirnya (maulud). Dengan demikian, manusia, khususnya umat Islam, patut meyakini bahwa mencintai Rasulullah tergolong karakter mulia dalam perhubungannya dengan Rasulullah.

Karakter mulia itu pun termaktub di dalam hadits Rasulullah berikut ini.

Dari Abu Hurairah r.a. bahwa Nabi Muhammad Saw. bersabda, "Demi Zat yang diriku dalam kekuasaan-Nya, seseorang tak dianggap beriman hingga aku lebih dicintainya dari orang tua dan anaknya," (H.R. Bukhari).

Sabda Rasulullah di atas adalah petunjuk bagi umatnya. Mencintai Baginda Rasul jauh lebih utama daripada mencintai segala sesuatu yang lain. Dengan demikian, ajaran agama Islam memang memberikan keutamaan dalam mencintai Rasulullah. 


\section{Mengharapkan Syafaat dari Rasulullah}

Melalui SGMA, Haji (Malik \& Junus, 2000) juga menitipkan amanat agar manusia senantiasa mengharapkan syafaat dari Rasulullah. Amanat itu terdapat pada bait 95 syair tersebut.

Ayuhai Nabi Rasul yang mulia

Harapkan syafaat kita 'kan dia

Padang mahsyar berhimpun manusia

Menghukumkan kita Tuhan Yang Kaya

Menurut bait syair di atas, manusia dapat mengharapkan syafaat (bantuan) dari Rasulullah pada hari perhitungan di Padang Mahsyar kelak. Pada hari perhitungan itu manusia akan diadili oleh Allah sesuai dengan perbuatan masing-masing ketika hidup di dunia. Oleh sebab itu, memohon syafaat dari Rasulullah sangat dianjurkan agar manusia bebas dari hukuman Allah karena perbuatan dosa masing-masing.

Dari Abu Hurairah bahwa Rasulullah Saw. bersabda, “... Maka, aku (Nabi Muhammad) pergi dan mendatangi Tahtal 'Arsy (ke bawah 'Arsy). Lalu, aku bersujud kepada Rabb-ku. Kemudian, Allah memberiku pertolongan dan pemberitahuan yang tak pernah Dia berikan kepada seseorang pun sebelum aku. Dia berfirman, "Wahai Muhammad, angkatlah kepalamu. Mintalah, maka engkau akan diberi. Mintalah syafaat, maka engkau akan diizinkan untuk memberi syafaat." Lalu, aku mengangkat kepalaku, dan aku mengatakan, "Ya, Allah. Tolonglah umatku! Tolonglah umatku!" (H.R. Muslim).

Sabda Rasulullah yang dipetik di atas merupakan sebagian rujukan kebenaran berkenaan dengan izin Allah kepada Rasulullah untuk memberikan syafaat kepada umatnya di akhirat kelak. Hal itu bermakna wasiat Raja Ali Haji melalui Syair Sinar Gemala berasal dari ajaran yang dibawa oleh Baginda Rasulullah. Dengan demikian, nilai karakter mengharapkan syafaat dari Rasulullah sejalan dengan ajaran Islam.

\section{Berdoa melalui Rasulullah}

Dalam SGMA (Malik \& Junus, 2000) ditemukan juga ajakan dan ajaran agar manusia berdoa melalui Rasulullah. Karena Baginda paling dicintai Allah, doa yang ditujukan kepada Allah dan disampaikan melalui Rasulullah (tawasul) akan lebih mungkin dikabulkan Allah. Di dalam doa itu diharapkan umat Islam terhindar dari segala kejahatan, baik yang bersumber dari diri sendiri maupun berasal dari pihak lain. Petikan syair bait 96 sebagai berikut.

Ayuhai Nabi junjunganku

Tiadalah lain pengharapan aku

Hanyalah tuan mahkotaku

Melepaskan dari kejahatan laku

Demikianlah harapan yang disampaikan oleh Haji dalam bentuk doa melalui karyanya. Dengan itu, secara tersirat beliau menitipkan wasiat bahwa manusia seyogianya senantiasa berdoa kepada Allah melalui Rasulullah agar terhindar dari segala kejahatan, baik kejahatan diri sendiri maupun kejahatan yang berasal dari orang atau makhluk lain. Kenyataan itu sejalan dengan firman Allah berikut ini.

"Sungguh, telah datang kepadamu seorang rasul dari kaummu sendiri, berat terasa olehnya penderitaanmu, sangat menginginkan (keimanan dan keselamatan) bagimu, amat belas kasihan lagi penyayang terhadap orangorang mukmin," (Q.S. At-Taubah, 128).

Melalui firman-Nya di atas, Allah menyebutkan sifat-sifat terpuji yang dimiliki oleh Baginda Rasul. Di antaranya, Baginda sangat penyayang dan menginginkan keselamatan bagi orang-orang yang beriman. Oleh sebab itu, melalui doa yang tulus dan ikhlas, sangat berkemungkinan permohonan orang-orang beriman kepada Allah, melalui Rasulullah Saw., akan dikabulkan oleh Allah. Jadi, berdoa kepada Allah melalui Rasulullah tergolong karakter mulia. 


\section{KESIMPULAN}

Karya Raja Ali Haji memuat tiga belas nilai pendidikan karakter terhadap Rasulullah. Ketiga belas nilai itu tersebar dalam lima karya yang dianalisis dalam penelitian ini. Dalam hubungannya dengan Rasulullah, manusia, khususnya umat Islam, dianjurkan agar menerapkan ketiga belas karakter mulia itu.

Nilai pendidikan karakter terhadap Rasulullah dapat diterapkan dalam pembelajaran pendidikan karakter. Sebaiknya, materinya digunakan dalam pelaksanaan pendidikan karakter, baik dalam pendidikan informal, formal, dan nonformal.

\section{UCAPAN TERIMA KASIH}

Tim peneliti mengucapkan terima kasih kepada Lembaga Penelitian dan Pengabdian kepada Masyarakat, Universitas Maritim Raja Ali Haji, yang telah membiayai pelaksanaan Penelitian Unggulan Perguruan Tinggi ini. Semoga hasilnya berguna dalam upaya-upaya membina generasi Indonesia yang berkarakter tangguh dan terhindar dari penetrasi budaya asing yang negatif.

\section{REFERENSI}

Ahmad, R., \& Haji, R. (1982). Tuhfat alNafis. Kuala Lumpur: Penerbit Fajar Bakti Sdn. Bhd. .

Alfan, M. (2011). Filsafat Etika Islam. Bandung: Pustaka Setia.

Aminuddin. (1997). Stilistika: Pengantar memahami bahasa dalam karya sastra. Semarang: IKIP Semarang Press.

Ary, D., Jacobs, L., \& Razavieh, A. (1982). Pengantar Penelitian dalam pendidikan. Terjemahan Furchan, A. . Surabaya: Usaha Nasional.

Bachmid, A. (2005). Aktualisasi NilaiNilai Islam dalam "Gurindam Dua Belas" Karya Raja Ali Haji. Buletin Al-Turas, 201-219.
Bakar, A. (2006). Aplikasi Teori Semiotika dalam Seni Pertunjukan. Etnomusikologi, Vol. 2, No. 1 , 4551.

Braginsky, V. (1994). Erti Keindahan dan Keindahan Erti dalam Kesusastraan Melayu Klasik. Kuala Lumpur: Dewan Bahasa dan Pustaka.

Cobley, P., \& Jansz, L. (1999). Introducing Semiotics. New York: Icon Books-Totem Books.

Eco, U. (1976). A Theory of Semiotics. . Bloomington: Indiana University Press.

Gazalba, S. (1981). Sistematika Filsafat: Buku IV. Jakarta: NV Bulan Bintang.

Haji, R. (1847). Gurindam Dua Belas. Batavia: Indonesia.

Haji, R. (1987). Kitab Pengetahuan Bahasa: Kamus Logat Melayu Johor, Pahang, Riau, dan Lingga. Pekanbaru: Bagian Proyek Penelitian dan Pengkajian Kebudayaan MelayuPenelitian dan Pengkajian Kebudayaan Nusantara, Departemen Pendidikan dan Kebudayaan.

Haji, R. (1989). Syair Abdul Muluk. Dalam Syamsiar, S. (Ed.) . Pekanbaru: Bagian Proyek Penelitian dan Pengkajian Kebudayaan Melayu, Penelitian dan Pengkajian Kebudayaan Nusantara, Departemen Pendidikan dan Kebudayaan .

Haji, R. (2013). Tsamarat Al-Muhimmah. Tanjungpinang: Dinas Pariwisata dan Ekonomi Kreatif, Pemerintah Kota Tanjungpinang.

Innis, R. (1982). Semiotics: An Introductory Anthology. Bloomington: Indiana University Press.

Pusat Kurikulum. (2010). Panduan Sistem Pelatihan Pengembangan Pendidikan Budaya dan Karakter Bangsa Melalui Pembelajaran aktif. Jakarta: Badan Penelitian dan 
Pengembangan, Kementerian Pendidikan Nasional.

Lapsley, D. (2016). On The Prospects for Aristotelian Character Education. J. Moral Educ. 45, https://doi.org/10.1080/03057240.2 016.1236721, 502-515. .

Littlejohn, S. (1996). Theories of Human Communication. New York: Wadsworth Publishing Company.

Mahdini. (1999). Tsamarat al-muhimmah: Pemikiran Raja Ali Haji tentang Peradilan. Pekanbaru: Yayasan Pusaka Riau.

Malik, A. (2008, December 11). rajaalihaji.com Corporation. Retrieved from rajaalihaji.com Web Site: http://www.rajaalihaji.com

Malik, A. (2008, December 11). Menelusuri Tempat Asal Bahasa Indonesia. Retrieved from rajaalihaji.com: http://www.rajaalihaji.com

Malik, A. (2012). Menjemput Tuah Menjunjung Marwah. Depok: Komodo Books.

Malik, A. (2012). Nilai-Nilai Budi Pekerti di dalam Karya-Karya Raja Ali Haji. Seminar Lembaga Adat Melayu Provinsi Kepulauan Riau (pp. 1-25). Tanjungpinang: Dinas Kebudayaan Provinsi Kepulauan Riau.

Malik, A. (2013). Raja Ali Haji: Tsamarat Al-Muhimmah. Tanjungpinang. Tanjungpinang: Dinas Pariwisata dan Ekonomi Kreatif, Pemerintah Kota Tanjungpinang.

Malik, A. (2014). Warisan Pemartabat Negeri: Mengapakah Sepi Apresiasi? Batam: Batam Pos.

Malik, A. (2015). Kehalusan Budi dalam Karya Raja Ali Haji, Tesis Ph.D Universiti Pendidikan Sultan Idris. Perak, Malaysia: Universiti Pendidikan Sultan Idris.
Malik, A. (2015). Nilai-Nilai Budi Pekerti dalam Karya Raja Ali Haji . Jurnal Peradaban Melayu, 96-107.

Malik, A., \& Junus, H. (2000). Studi Tentang Himpunan Karya Raja Ali Haji. Pekanbaru: Badan Perencanaan Pembangunan Daerah, Propinsi Riau dan Pusat Penelitian Kebudayaan dan Kemasyarakatan, Universitas Riau.

Malik, A., \& Shanty, I. (2017). Personal Character Index in the Works of Raja Ali Haji . The International Journal of Social Science, 22-34.

Malik, A., \& Shanty, I. (2019). Character Indexes of the People in the Works of Raja Ali Haji. Advances in Social Science, Education and Humanities Research 295, 148151.

Malik, A., Dahnuss, D., \& Shanty, I. (2019). Implementasi Pendidikan Karakter di Lingkungan Keluarga Masyarakat Sebauk. Anugerah, 17.

Malik, A., Subroto, G., Shanty, I., \& Agust, S. (2020). Character Indices to the Family in the Works of Raja Ali Haji. Internastional Journal of Innovation, Crativity and Change, 1197-1214.

Matheson, V. (1982). Tuhfat al-Nafis. Kuala Lumpur: Penerbit Fajar Bakti Sdn. Bhd.

Nor, M. R., \& Dahlan, A. (2018). The activism and Survival of the RiauLingga 'Ulama' in the dutch east indies colonial era. Journal of indonesian islam, 69-84.

Pateda, M. (2001). Semantik leksikal. Jakarta: Rineka Cipta.

Peirce, C. (1982). Logic as Semiotics: The Theory of Signs. Bloomington: Indiana University Press.

Preminger, A. (. (1974). Princeton encyclopedia of poetry and poetics. London: The Maxmillan Press Ltd.

Rahman, J., Ahzar, A., Malik, A., Sarjono, A., Hafrizal, R., \& (Ed.). (2010). 
Dermaga sastra Indonesia: Kepengarangan Tanjungpinang dari Raja Ali Haji hingga Suryatati A. Manan. Depok: Komodo Books. Santosa, P. (1993). Ancangan Semiotika dan Pengkajian Susastra. Bandung: Angkasa.

Sobur, A. (2006). Semiotika Komunikasi. Bandung: Remaja Rosdakarya.

Stephenson, M. (2000). Analisis Isi. Terjemahan Diah, M. Pekanbaru: Balai Bahasa Pekanbaru, Pusat Bahasa, Departemen Pendidikan Nasional.

Syamsiar, S. (1989). Syair Abdul Muluk. Pekanbaru: Bagian Proyek Penelitian dan Pengkajian Kebudayaan Melayu, Penelitian dan Pengkajian Kebudayaan Nusantara, Departemen Pendidikan dan Kebudayaan.
Trochim, W. (2000). Penelitian Kualitatif. Terjemahan M. Diah. Pekanbaru: Balai Bahasa Pekanbaru, Pusat Bahasa, Departemen Pendidikan Nasional.

Yazdi, M. (2012). 22 Nasihat Abadi Penghalus Budi. Jakarta: Citra.

Yunus, R. (. (1987). Kitab pengetahuan Bahasa: Kamus Logat Melayu Johor, Pahang, Riau, dan Lingga. Pekanbaru: Penelitian dan Pengkajian Kebudayaan Nusantara, Departemen Pendidikan dan Kebudayaan.

Zoest, A. (1993). Semiotika: Tentang Tanda, Cara Kerjanya, dan Apa yang Kita Lakukan dengannya. Jakarta: Yayasan Sumber Agung.

Zuriah, N. (2008). Pendidikan Moral dan Budi Pekerti dalam Perspektif Perubahan. Jakarta: Bumi Aksara. 